\title{
A Multi-criteria Approach in the Project Selection Process in Multi-Project Context
}

\author{
Charles Éric Manyombé ${ }^{1}$ \& Sébastien H. Azondékon ${ }^{1,2}$ \\ ${ }^{1}$ Université du Québec en Outaouais, Canada \\ ${ }^{2}$ Research Group in Project Analysis, Production and Decision Support (GRAP2AD) \\ Correspondence: Charles Éric Manyombé, Université du Québec en Outaouais, Canada. \\ Received: April 1, 2021 \\ doi:10.5539/ibr.v14n6p125
}

\begin{abstract}
In a multi-project environment, organizational complexity refers to the difficulties that organizations often face in choosing projects to build their portfolios, since they do not aim to achieve the same strategic business objectives. It is for this reason that the project selection process requires the implementation of an effective decision-making tool when composing a project portfolio. The objective of this paper is to propose an adapted framework for a better project selection procedure inspired by the approaches of strategic relevance, profitability criteria, uncertainty, and risk analysis, the ability to dispose of scarce resources, and the determination of interdependencies between different projects.
\end{abstract}

Keywords: heuristic approach, model assumptions, multi-project management, project portfolio, selection process

\section{Introduction}

Today, project portfolio management is at the heart of the strategic processes of many companies and is seen as a means for organizations to achieve their strategic business objectives. As a result, in order to be effective in a highly competitive environment, it is important for organizations to implement multiple projects for which they can provide sufficient and appropriate resources. To do this, companies must use a rigorous and clear method when selecting projects.

In general, in the field of multi-project management, organizational complexity refers to the difficulties that organizations often face in choosing the projects that should make up their portfolios, since the latter do not aim to achieve the same objectives.

Consequently, projects should be chosen based on their relevance to the company, the organization's objectives, the adequacy between the number of projects, and the availability of resources, while ensuring that the right projects are undertaken and aligned with organizational objectives.

By looking at the problem of project selection in a multi-project context, Cooper and al., (1997), we're able to identify the main problems encountered in the selection of projects in a multi-project context which are, among others, the inadequacy of projects with the organization's strategies; an asymmetry between the projects selected and the organizational capacity; the low quality of the projects selected; the lack of synergy between projects and the imbalances caused by the choice of projects.

Beyond the aspects outlined above by Cooper and al., (1997), we can also add the strong propensity of multi-project organizations to select or retain projects that are highly risky or financially unprofitable.

Taking into consideration all its aspects, it then becomes clear that even if project portfolio management provides benefits that could not be obtained through the management of individual projects, it is clear that the selection of projects that make up the project portfolio remains a complex activity from the point of view of senior management.

This situation shows on the one hand that project selection is an approach that is at the heart of strategic business objectives and on the other hand highlights the main challenges faced by managers of multi-project organizations when selecting projects.

With regard to the impact that the project selection process has on the composition and management of a project 
portfolio, we wish to show, using a heuristic approach, how multi-project organizations could proceed in selecting investment projects to achieve their strategic business objectives.

\section{Literature Review}

According to Cooper and al., (1997), the project selection process in a project portfolio management context is a complex and difficult exercise. The challenge in this exercise usually lies in aspects such as retaining projects that are profitable for the organization, balancing each project portfolio in terms of the number of projects, and strategically aligning each project portfolio with the vision and mission of the organization.

About the issue of interdependencies in a multi-project context, Hoffman (2005), warns of the dangers that can arise when selecting projects. As a result, he indicates that problems in one project can harm the other projects in the portfolio. Taking this aspect into consideration it becomes important to specify that during project selection a benchmarking with existing projects is indispensable to reduce the number of mutually exclusive projects considerably to avoid wasting resources.

Along the same lines, Crawford (2006), argue that in a multi-project context, projects are supposed to be mutually supportive. In other words, the success of one project may depend on another project. To better illustrate their point of view, they take the example where projects may experience interdependencies in terms of resources. That is, the need to share resources or wait for limited resources to be freed up by a project.

In the view of Blau \& al., (2004), in project portfolio management, many projects are interdependent, and, in their view, these interdependencies need to be understood for effective decision-making in project selection.

Taking into consideration all its aspects we can admit that multi-project organizations need to be able to understand existing interdependencies between projects to make appropriate decisions during the project selection process.

According to Cooper et al., (1997a, 1997b, 1998), Archer \& Ghasemzhadeh (1999),

Dye \&Pennypacker (1999), Sommer (1999), Artto et al (2004), Morris \& Jamieson (2004), PMI (2006), have argued that cooperative efforts to select the right mix of projects require the examination of internal capacities and external opportunities and the optimization of scarce resources for the benefits of individual projects and the project portfolio.

Cooper \& al., (2000) argued that corporate strategy must be reflected in the project portfolio and the allocation of resources to projects. Like financial investment, the project portfolio requires balance.

Sharing this view, Cleland (1999) argued that projects are the cornerstone of business strategy design and implementation.

Along the same lines, Wheelwright \& Clark (1992) identified the importance of the right set of projects in the project portfolio for a company's future or market growth over time.

Kendall \& Rollins (2003) find that a company's strategic objectives can take many forms, such as improving profitability, increasing market share, complying with prescribed regulations, or improving services and penetrating new markets.

Empirical studies show that one of the critical factors leading to the failure of projects to implement business strategies is the selection and implementation of a very large number of projects beyond the capacity of organizations (Wheelwright \& Clark, 1992; Archer \& Ghasemzadeh, 1999; Englund \& Graham, 1999; Cooper et al., 2000; Yelin, 2005; Crawford et al., 2006; and Blichfeldt \& Eskerod, 2007).

Archer \& Ghasemzhadeh, (1996), Ghasemzhadeh \& Archer (2000) reveal that organizations face several challenges in project selection. Firstly, projects have conflicting objectives; some are tangible and some intangible, so it is not easy to compare and select.

Second, there are uncertainties associated with project parameters, costs, and risks. This makes it difficult to select the right projects that contribute to the successful implementation of the business strategy. Third, some projects are highly interdependent. This means that the organization cannot compare one project to others but a set of projects to others (Ghasemzadehet al., 1999).

Seen from this perspective, it becomes important to stress that selecting the right projects that fit with the organization's strategic objectives is not an easy task.

Given the importance of this issue and its impact on the success of the project portfolio, several authors have tried to contribute, but unfortunately, so far most of the proposed tools do not solve the problem, hence the need to propose a heuristic that will be a valuable tool in the hands of decision-makers to facilitate the project 
selection process within project-oriented enterprises.

\section{Conceptualization of the Parameters of the Heuristic Approach}

When selecting a project in a multi-project context, the point of view adopted by the decision-maker during the evaluation and decision-making process is to treat the various parameters such as strategic relevance, financial profitability, degree of uncertainty, and the nature of interdependencies as constraints that are imposed on it and which it should take into account in the decision-making process. In this case, the decision-maker in the presence of a multitude of investment projects has no choice but to select the project that satisfies the requirements imposed by the various parameters mentioned above.

The criterion or parameter of strategic relevance will require senior managers to determine a priori the goals and objectives of the organization in the short, medium, and long term. In other words, the decision-maker has to select projects that are in line with the meaning that one would like to give to the organization, from the brand image that one would like to reflect, to the market share that one wishes to occupy, in a word the strategy to be adopted is defined by the vision that the executives possess and this is what serves as a referential basis for them when they are in a project selection process in a multi-project environment

This parameter in this heuristic approach will be represented in the form of a utility function, which specifies that the value attributed to each risky investment project may vary from one company to another depending on the decision-makers attitude to risk and the information available to him.

The criterion or parameter of financial profitability, in this case, the decision-maker whose objective is to improve or increase the company's profit or profit margin will have to calculate the Net Present Value (NPV) of the different investment projects presented to him and then calculate the net economic profit, the profitability index, and the marginal Sorting when comparing projects with different time horizons for an informed decision on the selection of projects based on the criteria of financial profitability.

In this case, the net present value of the selected project should be understood as a certain equivalent in monetary value that the organization could obtain by accepting the investment project. It is these indices that help to guide the rational decision-makers decision. Given that if a risky investment project results in a non-negative Net Present Value, then it becomes profitable for the organization to retain that project. This would allow, under the principle of additively, to increase the financial profitability of the organization. It is also important to add to its profitability criteria the study of the conditional gain expected from the investment project, which gives a precise idea of the opportunity profile of the project being selected.

The criterion or parameter of uncertainty and the associated risks reveals the idea that during the project selection process, even if the financial profitability constraint is respected, the decision-makers choice could depend on both the operating risk and the financial risk. That is the total risk of the investment project. In such a context, the decision-making approach will require the decision-maker to determine in advance the actual total risk level that the company is prepared to bear. As far as our research problem is concerned, such risk will be more related to the financial risk and will depend both on the probability of a financial loss and the size of the financial loss in the event that the investment project proves to be unprofitable. Under these conditions, the financial risk of any investment project will then be assessed based on two measures which are the probability of loss and the expected conditional loss of the investment project.

The criterion or parameter of interdependence between projects in addition to the criteria set out above, consideration of the nature of the existing relationships between the different projects is a determining parameter when making decisions in the project selection process in a multi-project environment. For this reason, the decision-maker will therefore be faced with choices between projects with incompatible or compatible relationships. Our study will take into consideration, on the one hand, incompatible projects, i.e. mutually exclusive projects, and on the other hand compatible projects which can be either independent or dependent depending on the purpose of the organization.

Once the parameters of the model have been stated, we can now proceed to the formulation of hypotheses.

\section{Model Assumptions}

We make the following assumptions:

1. The projects to be selected arrive randomly following a fish distribution and come from several sectors of activity.

2. Two projects are considered incompatible when the choice of one automatically leads to the rejection of the other. 
3. Two projects are considered independent if the choice of one does not influence the choice of the other.

4. The projects to be selected are incompatible or compatible with objectives that differ from one another.

5. The financial profitability of the projects will be assessed based on NPV, marginal IRR, expected conditional gain, and net economic profit.

6. For independent projects, the decision-maker will accept projects with an NPV greater than zero.

7. For mutually exclusive projects, the decision-maker will select the project with the highest positive NPV.

8. The decision-maker will further penalize a project that is considered risky.

9. The decision-makers utility curve is exponential.

\subsection{Underlying Assumptions}

It is assumed that there are experts in the organization capable of calculating its parameters for each project.

An investment project will be considered acceptable if:

- Its expected NPV is greater than zero.

- The total effective risk does not exceed a pre-determined threshold value.

- Its expected conditional gain is all the higher.

- Its expected conditional loss is lower.

- It satisfies the decision-makers utility function.

\subsection{Heuristic Approach}

To select the right projects that fit with the organization's strategic business objectives, we will propose a heuristic inspired by the exponential utility function.

This function explains that if the decision-makers utility curve is exponential, he can analyze and evaluate each project individually if they are independent in terms of probability. Consequently, it then becomes possible when selecting projects to determine the value and individual contribution of each project to the company's enrichment.

\subsubsection{Modeling of the Exponential Utility Function in the Choice of Projects in a Multi-Project Context}

\subsubsection{Evaluation Based on the Utility Function Criterion}

It is assumed that the expected utility for each independent project whose probability distribution follows a normal distribution of mean $\boldsymbol{\mu}_{\boldsymbol{X}}$ and deviation -type $\boldsymbol{\sigma}_{\boldsymbol{x}}$ and for which the decision-makers utility curve is exponential with a risk aversion coefficient equal to $\mathbf{c}$.

$$
\mathrm{E}\left[U\left(X_{t}\right)\right]=1-\exp \left[-\frac{1}{2}\left(2 c \mu_{x}-c^{2} \sigma_{x}^{2}\right)\right]
$$

Then the certain monetary equivalent corresponding to this utility is calculated and is equal:

$$
\widehat{X}=\mu_{X}-\frac{c}{2} \sigma_{X}^{2} \quad(\mathrm{x} \$)
$$

The estimate of the decision-makers aversion coefficient $\mathrm{c}$ is obtained by determining the value of a point on the utility curve that is a function of the project's contribution to the achievement of strategic business objectives other than financial profitability. This may be the share of the market that the company wishes to occupy or the brand image that it would like to convey.

$$
\mathrm{C}=\frac{-\ln \left[1-\cup\left(X_{\alpha}\right)\right]}{X_{\alpha}}
$$

With $\boldsymbol{\mu}_{\boldsymbol{X}}$ : the average execution time of a sequence of activities project 
$\boldsymbol{\sigma}_{x}^{2}$ : The variance of this average duration.

C: the estimation of the aversion coefficient.

After this evaluation, the decision-maker moves on to the second stage, which is the evaluation of financial profitability.

\subsubsection{Evaluation Based on the Criterion of Financial Profitability}

The Net Present Value (NPV) is a measure at today's date of the expected enrichment of the financial transaction in a company. It makes it possible to determine whether the project is selected will bring added value to the organization from a financial point of view.

The mathematical expression of NPV is as follows:

$$
\mathbf{V A N}=-I_{0}+\frac{\sum_{i=1}^{n} F M_{i}}{(1+k)^{n}}
$$

With $\mathrm{I}_{0}$ : Initial investment at time 0

FM: net cash flow at the time i

$\mathrm{K}$ : required rate of return

n: number of periods over which the project extends

If VAN $\geq \mathbf{0}$

In this case, the conditional gain equation of the investment project can be combined with the probability function of its NPV.

The function of the Conditional Gain of the investment project is therefore expressed as follows:

4.2.1.3 Expected Conditional Gain of the Investment Project (GCE)

$$
\operatorname{GCE}=\mu_{x} P_{r}(\widetilde{V A N} \geq 0)+\sigma_{x} \frac{1}{\sqrt{2 \pi}} e^{\frac{-1}{2}\left(\frac{\mu_{x}}{\sigma_{x}}\right)^{2}}
$$

It provides the expected value of the gain associated with the project should its net value become positive once the investment project is accepted and completed.

$$
\text { With: e=2.721; } \quad \pi=3.14 P_{r}(\widetilde{V A N} \geq 0)
$$

This represents the probability that the NPV of the investment project is greater than or equal to zero, i.e. that the investment project is financially profitable.

This probability is calculated as follows:

$$
\begin{gathered}
P_{r}(\widetilde{V A N} \geq 0)=\left(\widehat{V A N}-\frac{\mu_{x}}{\sigma_{x}} \geq \frac{0-\mu_{x}}{\sigma_{x}}\right)= \\
P_{r}(\widetilde{V A N} \geq 0)=P_{r}\left(z \geq \frac{-\mu_{x}}{\sigma_{x}}\right)=P_{r}\left(z \leq \frac{\mu_{x}}{\sigma_{x}}\right)=\mathrm{T}\left(\frac{\mu_{x}}{\sigma_{x}}\right)
\end{gathered}
$$

Where: $\mathbf{T}\left(\frac{\mu_{x}}{\sigma_{x}}\right)$ which corresponds to the value read in the table of the reduced centered normal distribution and expresses the probability that the investment project is financially profitable.

This value $\boldsymbol{P}_{\boldsymbol{r}}$ is read from the table of the reduced centered normal distribution.

The expected conditional gain determines the gain that could be expected if the investment project proves to be profitable over its lifetime.

4.2.1.4 Evaluation of the Financial Risk Associated with the Investment Project

Such a financial risk will depend both on the probability of a financial loss as well as the size of the financial loss if the investment project proves to be financially unprofitable. Its net present value takes on a negative value.

The probability of loss of the investment project (PP), which is expressed as follows: 


$$
\begin{gathered}
\mathrm{PP}=\boldsymbol{P}_{r}(\widetilde{V A N} \leq \mathbf{0})=\left(\widehat{V A N}-\frac{\mu_{x}}{\sigma_{x}} \leq \frac{0-\mu_{x}}{\sigma_{x}}\right) \\
=P_{r}(\widetilde{V A N} \leq \mathbf{0})=P_{r}\left(z \leq \frac{-\mu_{x}}{\sigma_{x}}\right)=P_{r}\left(z \geq \frac{\mu_{x}}{\sigma_{x}}\right)=1-\mathrm{T}\left(\frac{\mu_{x}}{\sigma_{x}}\right)
\end{gathered}
$$

Where: $\mathbf{T}\left(\frac{\boldsymbol{\mu}_{x}}{\boldsymbol{\sigma}_{\boldsymbol{x}}}\right)$ which corresponds to the value read in the table of the reduced centered normal distribution. $\mathbf{1}$ $\mathbf{T}\left(\frac{\boldsymbol{\mu}_{x}}{\sigma_{x}}\right)$ which expresses the probability that the investment project is financially unprofitable.

4.2.1.5 Expected Conditional Loss of the Investment Project

It is expressed as follows:

$$
\begin{gathered}
\text { PCE } \quad=\mu_{x} P_{r}(\widetilde{V A N} \leq 0)-\sigma_{x} \frac{1}{\sqrt{2 \pi}} e^{\frac{-1}{2}\left(\frac{\mu_{x}}{\sigma_{x}}\right)^{2}} \\
P_{r}(\widetilde{V A N} \leq 0)=\left(\widehat{V A N}-\frac{\mu_{x}}{\sigma_{x}} \leq \frac{0-\mu_{x}}{\sigma_{x}}\right)=P_{r}(\widetilde{V A N} \leq 0) \\
=P_{r}\left(z \leq \frac{-\mu_{x}}{\sigma_{x}}\right)=P_{r}\left(z \geq \frac{\mu_{x}}{\sigma_{x}}\right)=1-\mathrm{T}\left(\frac{\mu_{x}}{\sigma_{x}}\right)
\end{gathered}
$$

It provides the expected value of the loss $\mathrm{f}$ associated with the project if the net value becomes negative once the investment project is accepted and completed.

\section{Conclusion}

In the project selection process in a multi-project context, the choice of projects systematically calls for the comparison of projects with objectives that do not necessarily converge but share a common pool of resources. In such a context, decision-makers must evaluate in advance the different types of projects and select those that will contribute to the achievement of their strategic objectives. In order to achieve this objective, given its importance, the decision-maker must be sufficiently equipped to approach this complexity with much greater realism and objectivity. It is to contribute to this problem, which today constitutes a headache for those in charge of organizations, that we have proposed this heuristic which will be a valuable tool in the hands of decision-makers.

Such a heuristic has multiple implications in practice as well as many inputs. The first advantage is that it considerably simplifies profitability calculations and avoids having to resort to complicated statistical methods of constrained optimization.

The second advantage is that it enables the managers of project-oriented companies to make informed decisions regarding the selection of projects and subsequently to better prioritize them. However, we are aware that for this tool to take off it would have been more appropriate to address the notion of a manager competency matrix and the project requirements matrix so that the decision-maker can be reassured that any selected project will not encounter any problem in terms of scarce resources when composing the various project portfolios. This is the limitation that could be attributed to the present research, but which will be addressed in our next work on the project portfolio optimization model.

\section{References}

Archer, N. P., \& Ghasemzadeh, F. (1996). Project Portfolio Selection Techniques: A review and Suggested Integrated Approach. In Dye, L. D., \& Pennypacker, J. S. (Eds.), (1999) Project Portfolio Management: Selecting and Prioritizing Projects for Competitive Advantage, pp. 207-238. West Chester, PA: Center for Business Practices. https://doi.org/10.1016/S0263-7863(98)00032-5

Archer, N. P., \& Ghasemzadeh, F. (1999). An Integrated Framework for Project Portfolio Selection. International Journal of Project Management, 17(4), 207-216. https://doi.org/10.1016/S0263-7863(98)00032-5

Artto, K. A., Dietrich, P. H., \& Nurminen, M. I. (2004). Strategy by Implementation of Projects. In D. P. Slevin, J. K. Pinto, \& D. I. Cleland (eds). (2004). Innovations-Project Management Research 2004, chapter 7. Newtown Square, PA: PMI. 
Blau, G. E., Pekny, J. F., Varma, V. A., \& Bunch, P. R. (2004). Managing a portfolio of interdependent new product candidates in the pharmaceutical industry. Journal of Product Innovation Management, 21(4), 227-245. https://doi.org/10.1111/j.0737-6782.2004.00075.x

Blichfeldt, B. S., \& Eskerod, P. (2007). Project Portfolio Management -There's More to It than What Management Enacts. International Journal of Project Management, in press, corrected proof. https://doi.org/10.1016/j.ijproman.2007.06.004

Cleland, D. I. (1999). The Strategic Context of Projects. In Dye, L. D., \& Pennypacker, J. S. (Eds.), (1999) Project Portfolio Management: Selecting and prioritizing projects for competitive advantage, pp. 3-22. West Chester, PA: Center for Business Practices.

Cooper, M. C., Lambert, D. M., \& Pagh, J. D. (1997). Supply Chain Management: More Than a New Name for Logistics. The International Journal of Logistics Management, 8(1). https://doi.org/10.1108/09574099710805556

Cooper, R. G., Edgett, S. J., \& Kleinschmidt, E. J. (1998). "Best Practices for Managing R \& D Portfolios," Research Technology Management, 41(4), 20-33. https://doi.org/10.1080/08956308.1998.11671219

Cooper, R. G., Scott, J. E., \& Elko, J. K. (2000). New problems, new solutions: making portfolio management more effective. Research-Technology Management, 43(2), 18-33. https://doi.org/10.1080/08956308.2000.11671338

Cooper, R., Edgett, S., \& Kleinschmidt, E. (1997a), Portfolio management in new product development: lessons from the leaders I. Research Technology Management, 40(5), 16-28. https://doi.org/10.1080/08956308.1997.11671152

Cooper, R., Edgett, S., \& Kleinschmidt, E., (1997b), Portfolio management in new product development: lessons from the leaders II. Research Technology Management, 40(6), 43-52. https://doi.org/10.1080/08956308.1997.11671170

Crawford, L., Hobbs, B., \& Turner, J. R. (2006). Aligning Capability with Strategy: Categorizing Projects to Do the Right Projects and to Do Them Right. Project Management Journal, 37(2), 38-50. https://doi.org/10.1177/875697280603700205

Dye, L. D., \& Pennypacker, J. S. (eds.). (1999). Project Portfolio Management: Selecting and prioritizing projects for competitive advantage. West Chester, PA: Center for Business Practices.

Englund, R. L., \& Graham, R. J. (1999), From Experience: Linking Projects to Strategy. Journal of Product Innovation Management, 16(1), 52-64. https://doi.org/10.1111/1540-5885.1610052

Ghasemzadeh, F., \& Archer, N. P. (2000). Project Portfolio Selection Through. Decision Support Systems, 29(1), 73-88. https://doi.org/10.1016/S0167-9236(00)00065-8

Ghasemzadeh, F., Archer, N., \& Iyogun, P. (1999). A Zero-One Model for Project Portfolio Selection and Scheduling. The Journal of the Operational Research Society, 50(7), 745-755. https://doi.org/10.1057/palgrave.jors.2600767

Hoffmann, W. H. (2005). How to manage a portfolio of alliances. Long Range Planning, 38, 121-43. https://doi.org/10.1016/j.lrp.2005.03.001

Kendall, G. I., \& Rollins, S. C. (2003). Advanced Project Portfolio Management and the PMO, Multiplying ROI at Warp Speed. Boca Raton, FL: J. Ross Publishing, Inc.

Morris, P., \& Jamieson, A. (2004). Translating Corporate Strategy into Project Strategy: Realizing Corporate Strategy through Project Management. USA: PMI.

PMI. (2006). Standard for Portfolio Management. Newtwon Square, PA: Author.

Sommer, R. J. (1999). Portfolio Management for Projects: A New Paradigm. In Dye, L. D., \& Pennypacker, J. S. (Eds.), (1999) Project Portfolio Management: Selecting and Prioritizing Projects for Competitive Advantage, pp. 55-60. West Chester, PA: Center for Business Practices.

Wheelwright, S. C., \& Clark, K. B. (1992). Creating Project Plans to Focus Product Development. Harvard Business Review, 70(2), 70-82.

Yelin, K. C. (2005). Linking Strategy and Project Portfolio Management. In Levine, H. A. (Eds.), Project Portfolio Management: A practical guide to selecting projects, managing portfolios, and maximizing benefit, 
pp. 137-145. USA: Pfeiffer Wiley.

\section{Copyrights}

Copyright for this article is retained by the author(s), with first publication rights granted to the journal.

This is an open-access article distributed under the terms and conditions of the Creative Commons Attribution license (http://creativecommons.org/licenses/by/4.0/). 